\title{
METHODOLOGY FOR ASSESSING THE RISKS OF EMERGENCIES ON THE EAST SIBERIA - PACIFIC OCEAN OIL AND GAS MAIN PIPELINE
}

\author{
KOVSHOV S. V $\mathbf{V}^{1}$, ALIMHANOVA T. A ${ }^{2} \&$ KITSIS V. M ${ }^{3}$ \\ ${ }^{1,2}$ Saint Petersburg Mining University, St Petersburg, Russia \\ ${ }^{3}$ National Research Mordovia State University, Bol'shevistskaya st., Saransk, Russia
}

\begin{abstract}
The object of the study was the main pipeline in East Siberia - Pacific Ocean. The main pipeline works in difficult conditions, therefore the assessment of the risks of accidents is absolutely necessary. The combined risk assessment method consisting of the Checklist expert evaluation and the Fault Tree was used in the article. The Fault Tree sample was suggested for described case study. The standard Checklist questionnaire was revised and expanded from 10 to 50 questions, to get more accurate accidents' risk assessment. The scenario of pipeline depressurization frequencies was also considered. The actual emergencies and incidents registration form was proposed. The ranking of main pipeline sections by accident rate was carried out. The software for systematization risk assessment data and accurate accident predictions is planned to be created during further research.

KEYWORDS: Risk Assessment, Checklist Method, Fault Tree Method, Main pipelines, Oil \& Gas Transportation
\end{abstract}

Received: Aug 24, 2019; Accepted: Sep 14, 2019; Published: Jan 10, 2020; Paper Id.: IJMPERDFEB20202

\section{INTRODUCTION}

Pipe line transportation is the cheapest and most reliable way to deliver oil and gas to consumers [Stephenson and Agnew, 2016]. East Siberia - Pacific Ocean (ESPO) main pipeline with a length of $4740 \mathrm{~m}$ is an important way to deliver fuel to Asian and American consumers [Abramov et al., 2018; Gulakova et al., 2018; Vatansever, 2017]. The ESPO main pipeline route runs through an area, characterized by harsh environmental conditions, including complex engineering-geological, hydrological, geodynamic and seismic conditions. An accident at any ESPO facility can result in severe economic, environmental and social losses.

Various accidents and emergencies can occur during the transportation of hydrocarbons, oil and gas through pipelines [Bujok et al., 2018; Klimova, 2017]. Currently, there are a number of methods and techniques for quantitative and qualitative analysis and risk assessment of emergencies on trunk pipelines. The most popular of them are: Check-List, What-If, HAZID, HAZOP, FMECA, FTA, ETA, QRA [Cheraghi et al., 2019; Yuhui et al., 2018; Bai and Bai, 2017].

Each of the existing methods has its own advantages: from the simplicity of the questionnaire assessment [Eskander, 2018], due to expert perception of the state of the pipeline (Check-List, What-If methods), to the use of highprecision state sensors of various operation parameters of the facility with the automated making of appropriate corrections in the presence of deviations in work [Bayramov et al., 2016]. However, all these methods have one common drawback - the lack of a full-fledged ability to assess the specific proportion of accident factors of fundamentally different origin: anthropogenic [Zambrano et al., 2018a], natural [Zambrano et al., 2018b], structural, technological, etc. 


\section{PROPOSED METHODOLOGY}

A quantitative assessment of the risk of accidents includes an assessment of the frequency of possible accident scenarios, and an assessment of the possible consequences of the considered accident scenarios. In this case, the scenario of pipeline depressurization frequencies is considered (Table 1).

Table 1: Pipeline Depressurization Frequencies (from National Guidelines for Risk Assessment at Hazardous Production Facilities)

\begin{tabular}{|l|c|c|}
\hline \multirow{2}{*}{$\begin{array}{c}\text { Inner Diameter, } \\
\text { Mm }\end{array}$} & \multicolumn{2}{|c|}{ Depressurization Frequencies, year $^{\mathbf{- 1}} \cdot \boldsymbol{m}^{\mathbf{- 1}}$} \\
\cline { 2 - 3 } & Full Section Gap, Outflow from Two Pipe Ends & Outflow through the Hole \\
\hline$<75 \mathrm{~mm}$ & $1 \cdot 10^{-6}$ & $5 \cdot 10^{-6}$ \\
\hline From 75 to $150 \mathrm{~mm}$ & $3 \cdot 10^{-7}$ & $2 \cdot 10^{-6}$ \\
\hline$>150 \mathrm{~mm}$ & $1 \cdot 10^{-7}$ & $5 \cdot 10^{-7}$ \\
\hline
\end{tabular}

To analyze the possible causes of an accident at the oil pipeline, a logically organized graphic design is constructed (Figure 1), which demonstrates the interaction of system elements, the failure of which individually can lead to the appearance of an undesirable event. The assessment was carried out using the Fault Tree method. The result of the assessment is the value of the probability (valuepon the Figure 1) of an emergency that arises for various reasons at oil pipelines. The calculations were made according to the statistics of incidents' occurrence.

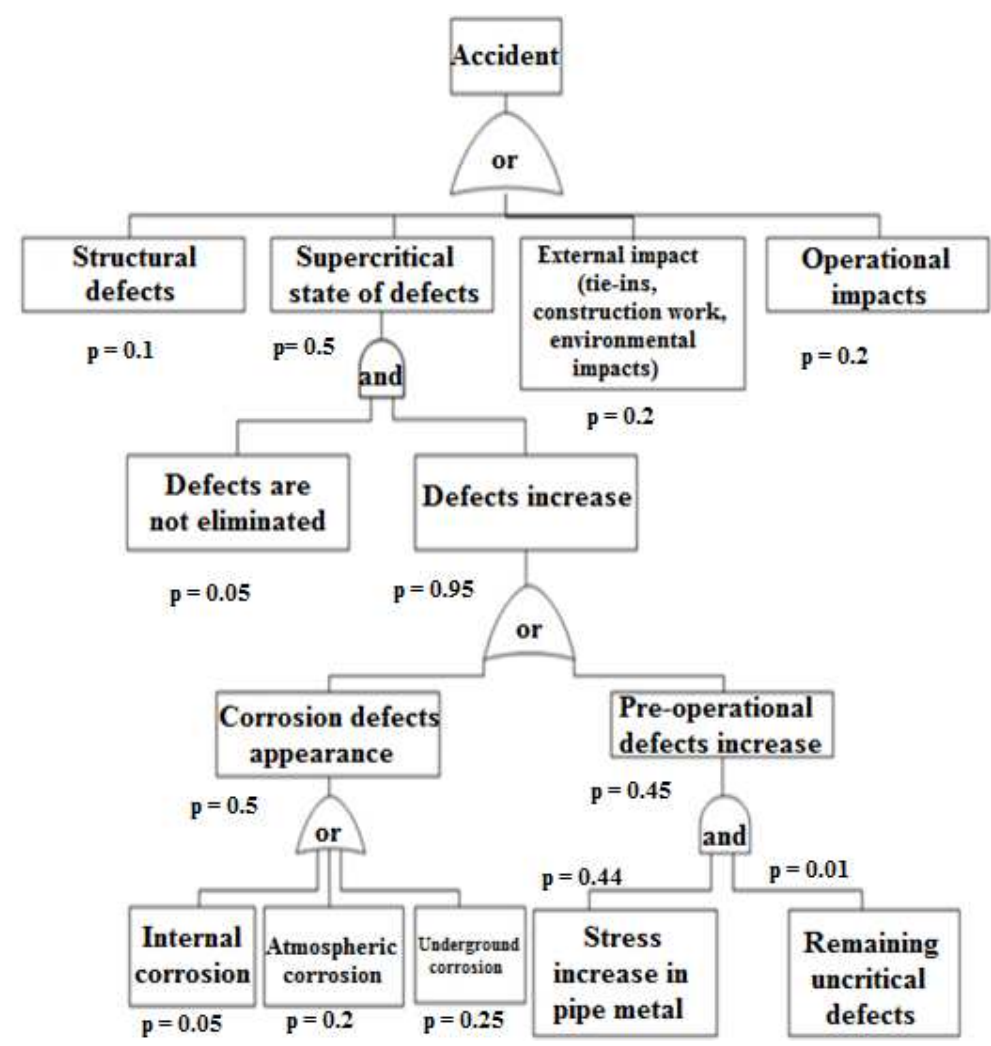

Figure 1: Fault Tree Sample with Probability of Emergencies.

The Figure 1 shows the main factors of emergency situation appearance. The highest probability was assigned to the 'defects increase' point, since in most cases it is a set of defects leading to the development of a major accident.

When assessing the state of the linear part of the main pipelines, experts use qualitative methods based on studying the compliance of the operating conditions of the facilities with the current industrial safety requirements. The most popular is the Check-list method, which consists of 10 basic questions. 
The questions used are often general, the answers to which are not able to fully reflect the actual degree of risk of accidents.

In order to prevent the impact of hazardous situations at the fuel and energy complex, it is proposed, adapted to Russian realities, the Check-List album questionnaire, a fragment of which is presented in Table 2. Questions are created on the basis of national safety standards and rules for trunk pipelines.

Table 2: The Sample of the Checklist Questionnaire

\begin{tabular}{|c|c|c|c|}
\hline $\begin{array}{l}\text { Sl. } \\
\text { No. }\end{array}$ & Parameter & Yes & No \\
\hline 1 & There are natural and/or artificial barriers on the linear part of the pipeline & & \\
\hline 2 & There are technological communication and power lines on the linear part of the pipeline & & \\
\hline 3 & There are along-route and access roads near the section of the linear part of the pipeline & & \\
\hline 4 & There are protective structures on the linear part of the pipeline & & \\
\hline 5 & There are bends to end consumers on the linear part of the pipeline & & \\
\hline 6 & There are water and condensate collectors on the linear part of the pipeline & & \\
\hline 7 & There are electrochemical protection systems on the linear part of the pipeline & & \\
\hline 8 & There is an emergency supply of pipes on the linear part of the pipeline & & \\
\hline 9 & There are houses of linear repairmen-signalmen on the linear part of the pipeline & & \\
\hline 10 & Pipes are welded & & \\
\hline 11 & Pipe diameter exceeds $800 \mathrm{~mm}$ & & \\
\hline 12 & There are lack of fusion and weld cracks & & \\
\hline 13 & Deviation from the nominal sizes exceeds the given / admissible values & & \\
\hline 14 & Ovality of pipe ends exceeds $1 \%$ & & \\
\hline 15 & The curvature of the pipes exceeds $1.5 \mathrm{~mm}$ per $1 \mathrm{~m}$ of length & & \\
\hline 16 & Total pipe curvature exceeds $0.2 \%$ of pipe length & & \\
\hline 17 & Pipe length within $10.5-11.6 \mathrm{~m}$ & & \\
\hline 18 & Visual inspection of the pipeline revealed external defects (cracks, rolling laps, delaminations) & & \\
\hline 19 & $\begin{array}{l}\text { There is delamination at the ends of the pipes and in the area of } 25 \mathrm{~mm} \text { from the ends of the } \\
\text { pipes }\end{array}$ & & \\
\hline 20 & $\begin{array}{l}\text { Welded pipe joints have a smooth transition from the base metal to the weld metal without } \\
\text { defects }\end{array}$ & & \\
\hline 21 & The ends of the pipes are cut at right angles and have a section for welding & & \\
\hline 22 & Pipes were tested successfully by hydrostatic pressure at the factory & & \\
\hline 23 & Welds were tested with non-destructive physical inspection methods & & \\
\hline 24 & Pipeline monitoring is carried out in a timely manner & & \\
\hline 25 & Scheduled repairs, interrepair maintenance and scheduled inspection are carried out & & \\
\hline 26 & Shapes and sizes of the seam are broken & & \\
\hline 27 & The pipeline is laid underground & & \\
\hline 28 & The pipeline is laid above the ground & & \\
\hline 29 & The pipeline is laid under water & & \\
\hline 30 & Soil has a direct effect on the linear part of the main pipeline & & \\
\hline 31 & The pipeline is affected by high / low temperature & & \\
\hline 32 & Flaw detector detects damage & & \\
\hline 33 & Plant roots affect the pipeline & & \\
\hline 34 & The pipeline section is separated from the compressor station & & \\
\hline 35 & Outside insulation in good condition & & \\
\hline 36 & The nearest settlements are within a radius of more than $2000 \mathrm{~m}$ & & \\
\hline 37 & The pipeline intersects with other pipelines & & \\
\hline 38 & There is a high soil aggressiveness & & \\
\hline 39 & Pipeline products are fire hazardous and explosible & & \\
\hline 40 & Pipeline products are toxic & & \\
\hline 41 & Pipeline products contribute to corrosion & & \\
\hline 42 & The working pressure in the pipeline complies with the standards & & \\
\hline 43 & Electrical safety is provided & & \\
\hline 44 & Pipeline with a diameter of $1020 \mathrm{~mm} / 1420 \mathrm{~mm}$ & & \\
\hline 45 & High probability of influence of anthropogenic factor & & \\
\hline
\end{tabular}




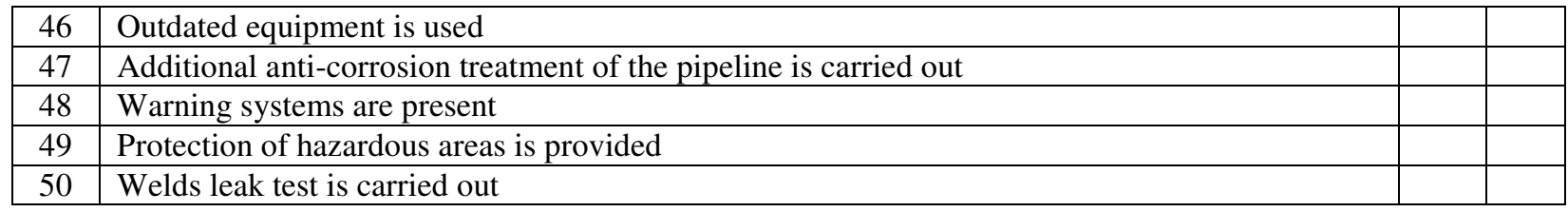

By filling out this checklist for the entire pipeline or for its individual section, the conditional safety level is easily determined by multiplying the number of positive responses by 2 . For example, if 40 out of 50 questions have a positive answer, then this means that the conditional safety level of the facility is estimated as $80 \%$.

Emergencies and accidents registration form.

For convenient visualization and further systematization, a modification of the existing methodology for a qualitative risk assessment is required.

Therefore, a form for registration of emergencies and incidents is proposed. The basis is the information of acts of investigation of emergencies and incidents on the section of the main pipeline.

The table is built on the example of accidents in mines registration form. The information on acts of investigation of emergencies and incidents on the section of the main pipeline is taken as the basis (Table 3 ).

Table 3: An Example of the Actual form of Accounting for Emergencies and Incidents in Individual Sections of Linear Pipelines

\begin{tabular}{|c|l|l|l|l|l|}
\hline $\begin{array}{c}\text { Sections of } \\
\text { Linear Main } \\
\text { Pipeline }\end{array}$ & \multicolumn{1}{|c|}{$\begin{array}{c}\text { Nature of } \\
\text { Damage }\end{array}$} & \multicolumn{1}{|c|}{ Cause } & Date & Consequences & $\begin{array}{c}\text { Emergency } \\
\text { Source }\end{array}$ \\
\hline 7 & Weld gap & Corrosion & 03.08 .15 & Oil leak & Technogenic \\
\hline 5 & $\begin{array}{l}\text { Appearance of } \\
\text { cracks }\end{array}$ & Unauthorized ties & 30.06 .15 & Oil leak & Anthropogenic \\
\hline 3 & Pipeline rupture & Railway accident & 09.11 .14 & Oil spill, fire & Anthropogenic \\
\hline 7 & $\begin{array}{l}\text { Corrosion } \\
\text { damage }\end{array}$ & $\begin{array}{l}\text { Chemical exposure of the } \\
\text { environment }\end{array}$ & 30.03 .15 & Oil leak & Natural \\
\hline 8 & Pipe defect & Violation of the rules of work & 10.02 .10 & Oil spill & Anthropogenic \\
\hline
\end{tabular}

Emergency situations at the facility are given more attention than incidents of various origins. Ignoring incidents is unacceptable, since it is their combination that leads to emergencies. Therefore, it is proposed to combine the actual form of accounting for acts of investigation of dangerous situations with the developed Check-List questionnaire to prevent the occurrence of large-scale emergencies on linear trunk pipelines. As a result, a hypothetical form for recording incidents and emergencies is proposed (Table 4).

Table 4: An Example of A Hypothetical form of Accounting for Emergencies and Incidents in Individual Sections of Linear Pipelines

\begin{tabular}{|c|c|c|c|c|c|}
\hline $\begin{array}{c}\text { Sections of } \\
\text { Linear Main } \\
\text { Pipeline }\end{array}$ & $\begin{array}{c}\text { On the Linear } \\
\text { Part of The } \\
\text { Pipeline There } \\
\text { are Artificial / } \\
\text { Natural Barriers }\end{array}$ & $\begin{array}{c}\text { on the Linear Part of } \\
\text { the Pipeline There Are } \\
\text { Technological } \\
\text { Communication And } \\
\text { Power Lines }\end{array}$ & $\begin{array}{c}\text { There } \\
\text { Are Lack } \\
\text { of Fusion, } \\
\text { Weld } \\
\text { Tears }\end{array}$ & $\begin{array}{c}\text { Flaw } \\
\text { Detector } \\
\text { Detects } \\
\text { Damage }\end{array}$ & $\begin{array}{c}\text { There are } \\
\text { Warning } \\
\text { Systems }\end{array}$ \\
\hline 1 & Yes & No & Yes & Yes & No \\
\hline 2 & No & No & No & No & Yes \\
\hline 3 & No & Yes & No & No & Yes \\
\hline 4 & Yes & Yes & Yes & No & No \\
\hline 5 & Yes & No & & No \\
\hline
\end{tabular}


This registration form greatly facilitates the risk analysis of hazardous production facilities on the methods used at the present stage in Russia. These methodologies prescribe the weight of each specified factors in the risk assessment system. The general conclusion about the emergency danger of the site is made depending on several factors in the aggregate: the probability of occurrence, answers to questions from the Check-list, the conditions of the pipeline, climateconditions, etc.

Thus, the sites are ranked by the level of risk of emergencies. On the example of the ESPO-1 and ESPO-2 oil pipelines, on the map of their location (Fig. 2), the checked sections are schematically marked, in the analysis of which natural, technological, and anthropogenic factors are taken into account.

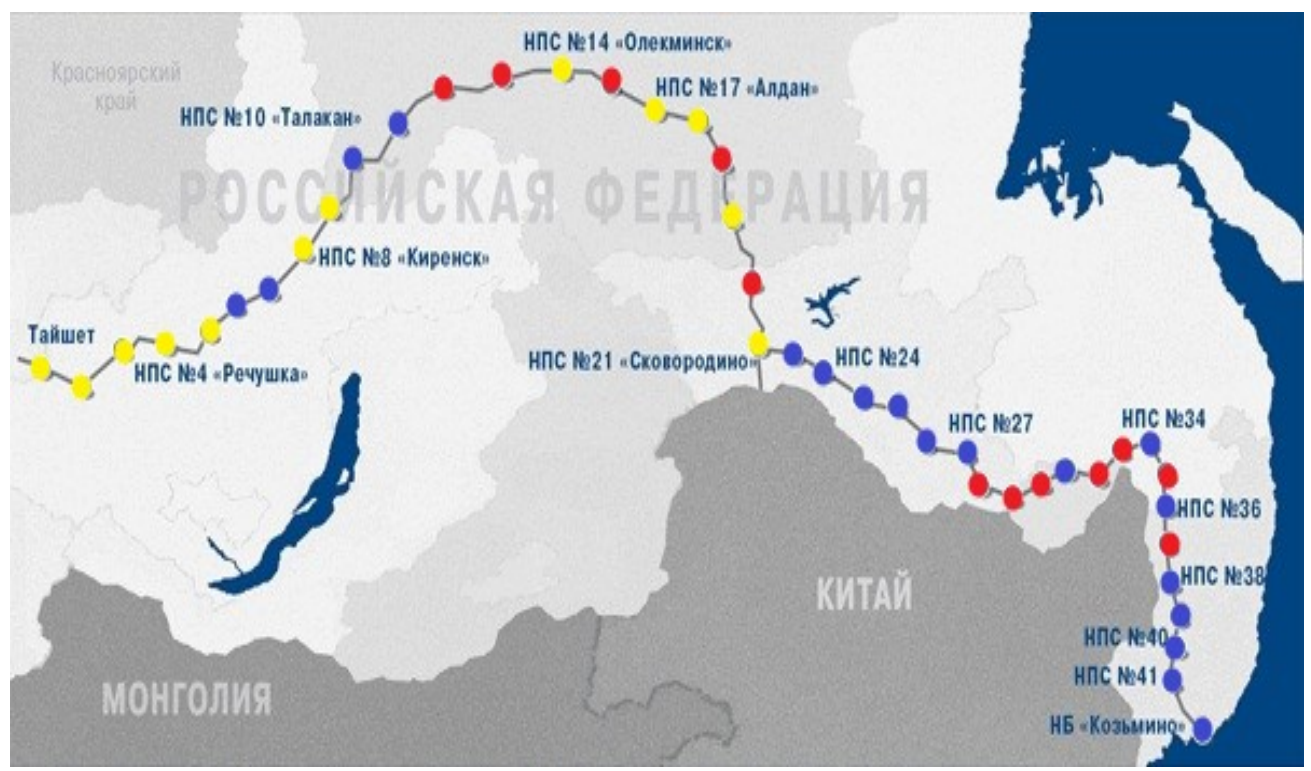

Figure 2: Ranking Sections of Trunk Pipelines by Accident Rate.

The calculation of the sites was made on the basis of the results of an expert assessment of the specialists of the Mining University, who evaluated these sites in accordance with the National methodological recommendations [РД 03418-01]. Blue areas indicate where the total risk score was less than 0.4, yellow - from 0.4 to 0.6. In red -more than 0.6.

\section{CONCLUSIONS}

This research was conducted to improve methodological approaches to the qualitative and quantitative analysis of the risk of main pipelines operation, namely: the development of sample questionnaires for creating the Check-List album, the development of recommendations on the use of quantitative methods for assessing the risks of emergencies at Russian facilities of the fuel and energy complex.

The pipeline depressurization frequencies were considered. The Fault Tree sample form was proposed, which could be successfully used for risk assessment of ESPO main pipeline damages. The suggested accidents registration form was used for emergency hazard estimation of the sections of ESPO main pipeline.

The proposed methodological approaches to assessing the risk of operation of trunk pipelines can be used to create a unified automatic database for predicting and recording incidents and accidents at the fuel and energy complex. In the future, it is planned to make a program that will systematize the data, which will most accurately reflect the values of risk indicators for complex technical systems. 


\section{REFERENCES}

1. Abramov, R. A., Tronin, S. A., Brovkin, A. V., Pak, K. C. (2018). Regional features of energy resources extraction in eastern Siberia and the far east. International Journal of Energy Economics and Policy, 8(4), 280-287.

2. Bai, Y. and Bai, Q. (2017). Safety of Risers, Pipelines, and Subsea Facilities. In Encyclopedia of Maritime and Offshore Engineering (eds J. Carlton, P. Jukes and Y. S. Choo). doi:10.1002/9781118476406.emoe362

3. Bayramov, E. R., Buchroithner, M. F., Bayramov, R. V. (2016). Multi-temporal assessment of ground cover restoration and soil erosion risks along petroleum and gas pipelines in Azerbaijan using GIS and remote sensing. Environmental earth sciences, 75(3), 256.

4. Bujok, P., Klempa, M., Yakubchik, M., Ryba, Y., Porzer, M. (2018). Possibilities of open eruption elimination by drilling tools. Journal of Mining Institute, 234, 624-629.

5. Klimova, I (2017). Instructional maps of safe working methods and practices for separate types of operations conducted in the oil mine. Journal of Mining Institute, 225, 354-359.

6. Cheraghi, M., Baladeh, A. E., \& Khakzad, N. (2019). A fuzzy multi-attribute HAZOP technique (FMA-HAZOP): Application to gas wellhead facilities. Safety science, 114, 12-22.

7. Kumar, S. N. (2014). Comparative Study of Performance, Combustion and Exhaust Emissions Analysis of Linseed Oil Based Biodiesel in a Ceramic Coated Diesel Engine. International Journal of Mechanical and Production Engineering Research and Development (IJMPERD), 4 (2), 75, 98.

8. Eskander, R. F. A. (2018). Risk assessment influencing factors for Arabian construction projects using analytic hierarchy process. Alexandria engineering journal, 57(4), 4207-4218.

9. Gulakova, O. I., Ershov, Y. S., Ibragimov, N. M., Novikova, T. S. (2018). Evaluation of the Public Efficiency of an Infrastructure Project: a case study of the Eastern Siberia-Pacific Ocean-2 Oil Pipeline. Regional Research of Russia, 8(2), 193-203.

10. Stephenson, S. R., and Agnew, J. A. (2016). The work of networks: Embedding firms, transport, and the state in the Russian Arctic oil and gas sector. Environment and Planning A: Economy and Space, 48(3), 558-576.

11. Vatansever, A. (2017). Is Russia building too many pipelines? Explaining Russia's oil and gas export strategy. Energy Policy, $108,1-11$.

12. Srikanth, D., Krishna, M. M., Ushasri, P., \& Murthy, P. K. (2013). Performance exhaust emissions, and combustion characteristics of cotton seed oil based biodiesel in ceramic coated diesel engine. International Journal of Mechanical Engineering, 2(5), 67-82.

13. Yuhui, Z., Shiyu, L., Lijing, Z., \& Gang, T. (2018, December). Natural Gas Pipeline Network Risk Assessment Based on FMECA-Fuzzy Comprehensive Analysis. In 2018 IEEE International Conference of Safety Produce Informatization (IICSPI) (pp. 11-15). IEEE.

14. Zambrano, C. J. R., Kovshov, S., \& Lyubin, E. (2018a). Assessment of anthropogenic factor of accident risk on the main oil pipeline Pascuales-Cuenca in Ecuador. Journal of Applied Engineering Science, 16(3), 307-312.

15. Zambrano, J., Kovshov, S. V., Lyubin, E. A. (2018b). Risk assessment of accidents due to natural factors at the PascualesCuenca multiple-use pipeline (Ecuador). Journal of Mining Institute, 230, 190-196.

16. Gopal, R., \& Chowdhury, R. G. (2014). Leadership styles and employee motivation: An empirical investigation in a leading oil company in India. International journal of research in business management, 2(5), 1-10.

17. РД 03-418-01. Guidelines for risk analysis of hazardous production facilities from 01-Sep-2001. Regulatory document of the 


\section{AUTHOR'S PROFILE}

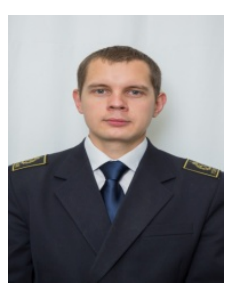

Stanislav V. Kovshov, was an Geographer, Department of Economic geography, Mordovian State University, Saransk, ussia in the year (2004-2008). He Passed internships at leading science research centers in Latvia (Riga), Finland (Lappeenranta), Poland (Krakow and Wroclaw), and Kazakhstan (Karaganda) (2008-2019). In the Year 2004-2008 he worked as Research Assistant, Department of Economic geography, Mordovian State University, Saransk, Russia. Principal Investigators: Prof. Vyacheslav P. Kovshov. Research topic: Recycling organic waste to biogumus, In 20082010: Safety Department, Saint-Petersburg State Mining University, Saint-Petersburg, Russia. Principal Investigators: Prof. Yuri V. Shuvalov. Research topic: Ecological safety, dust pollution problem, recycling organic waste, Industrial technogenic risks \& in 2010-2019: PhD, Safety Department, Saint-Petersburg mining university, Saint-Petersburg, Russia His $\mathrm{Ph} \mathrm{D}$ Theses project title is Biogenic techniques to reduce dust in mining production. He has an experience in the years 2005-2007: Engineer, BioWorm-KRV, Saransk, Russia, 2009-2010: Engineer, Safety Department, Saint-Petersburg State Mining University, Saint-Petersburg, 2010-2014: Assistant professor, Safety Department, Saint-Petersburg State Mining University, Saint-Petersburg and 2014-2019: Associate professor, Safety Department, Saint-Petersburg State Mining University, Saint-Petersburg. Lectures and practical classes on: "Health and Safety", "Noxology", "Industrial safety". The number of classes given annually: more than 200 hours. Research techniques and collaboration experience: Ecological Safety. Safety Management. Energy safety. Author of more than 120 scientific and educational works, including 1 monograph, 35 papers in international journals, 16 patents for the invention of the Russian Federation. There are degrees and awards from international exhibitions and conferences.

Special skills: English level B2



Takhmina A. Alimkhanova, currently working as Research Assistant in Safety Department, Saint Petersburg State Mining University, Saint Petersburg, Russia. Principal Investigators: Doc. Stanislav V. Kovshov. And also works as Assistant Professor in same Department from the year 2018. Research topic: Assessment of the risk of emergencies on trunk pipelines 2017-present: Safety Department, Saint-Petersburg State Mining University, Saint Petersburg Principal Investigators: Doc. Stanislav V. Kovshov. Research techniques and collaboration experience: Ecological Safety. Safety Management. Energy safety. Author of more than 10 scientific and educational works, 3 papers in the Russian Federation. There are degrees and awards from international exhibitions and conferences. Special skills: English level B2. 


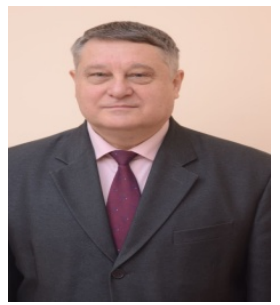

Vyacheslav M. Kitsis, 1971-1976: Geographer, teacher of geography, faculty of history and geography, Mordovian State University, Saransk, Russia. 1990-2018: internships Moscow state University. M. V. Lomonosova (Moscow), Ministry of ecology and nature management of the Republic of Mordovia (Saransk). 1979-1981: Junior researcher, research laboratory of engineering Geology, hydrology and nature protection, Mordovia state University, Saransk, Russia. Principal Investigators: Prof. Evdokimov Sergey Petrovich. Research topic: changes in the geological environment in connection with hydraulic engineering and urban construction of the non-Chernozem zone of the RSFSR. 1984-1987: Department of economic geography of the USSR, Moscow state University. M. V. Lomonosova, Moscow, Russia. Principal Investigators: Prof. Nikolsky Igor Vladimirovich, Prof. Alekseyev Alexander Ivanovich. Research topic: Territorial organization of trade and production complex of rural areas of the Mordovian ASSR. 1992-1997: candidate of geographical Sciences, Department of ecology and nature management, Mordovian state University, Saransk, Russia. Projects: Map of changes in the geological environment in connection with hydraulic engineering and urban construction of the non-Chernozem zone of the RSFSR (except for the Kaliningrad region, the Ural and TRANS-Ural mountains); Environmental passport of the enterprise. His Work experience were 1976-1979: headmaster, Odessa region, Ukraine. 1979-1981: Junior researcher, research laboratory of engineering Geology, hydrology and nature protection, Mordovian state University, Saransk, Russia. 1981-1984: senior lecturer, Saransk cooperative Institute, Saransk, Russia. 1988-2000: associate Professor, Saransk cooperative Institute, Saransk, Russia. 2000-2013: Dean of the faculty of international economic relations, Saransk cooperative Institute, Saransk, Russia. 2014-present: associate Professor of tourism Department, Mordovian state University, Saransk, Russia. Lectures and practical classes on the topics: "Protection of natural resources", "Economics of natural resources", "Organization and management of natural resources", "international tourism", "Tourism resource studies". Number of classes held annually: more than 800 hours. Research techniques and collaboration experience: Environmental economics. Environmental management. Nature protection. International tourism. The Economics of tourism. Author of more than 180 scientific and educational works, including 2 monographs, 1 textbook, 4 educational manuals. He have experience of participation in international conferences. 